\title{
Suitability of Igneous Rocks as Aggregates in Road Pavement Layers in Greece
}

\author{
N Depountis*, V Boumpoulis, G Mouzoulas and N Sabatakakis \\ Department of Geology, Laboratory of Engineering Geology, University of Patras, 26504 Patras, Greece
}

*Corresponding author: N Depountis, Department of Geology, Laboratory of Engineering Geology, University of Patras, 26504 Patras, Greece.

\section{Abstract}

This research focuses on accessing the suitability of specific igneous rocks for their potential use as aggregates in road pavement layers. During the current research, several quality control tests were carried out on andesite and dacite rocks, obtained from the areas of Methana and Agioi Theodoroi, approximately $60 \mathrm{Km}$ West of Athens, Greece. The quality control tests were conducted under the specific guidelines of Hellenic Technical Specifications (ELOT) for aggregate properties determination, while the procedure focused on the estimation of the following parameters:

1. Geometrical properties (grain size analysis, flakiness index, and sand equivalent value)

2. Physical properties (apparent density and water absorption)

3. Mechanical properties (Micro - Deval index, Los Angeles Abrasion Value, Aggregate Impact Value)

The laboratory testing results led to the general conclusion that the most samples obtained from the andesite and dacite rocks cannot be used as aggregates in road pavement layers, due to their high Los Angeles Abrasion Values (LAAV). High values of LAAV represent a low strength in mechanical corrosion and crush and contribute to the low quality of these geomaterials as aggregates. Some of the collected samples were determined as suitable for use in subbase road pavement layers, whereas some other samples were determined as suitable for use in base road pavement layers. Furthermore, correlations between the properties of the referred geomaterials were evaluated and empirical equations regarding the mechanical as well as their geometrical properties were established.

Keywords: Aggregates; Igneous rocks; LAAV; Pavement layers

\section{Introduction}

Aggregates are generally low cost classified natural materials, which are essential for the construction of infrastructure and buildings in urban areas [1] and are necessary for the preparation of concrete and mortars, in road pavement layers, road embankments, bituminous mixtures, track ballast, drainage and filter materials, and armour stones. At the same time, they are increasingly used in various environmental applications such as protection of soils from erosion, filters for water purification, the stability of natural and artificial slopes, and stabilization of landslides [2]. The role of road pavement layers is to receive loads from traffic and to distribute them back to the ground. The subbase layer protects the base layer from 'infection' from any soil material (clay, organic, etc.) and transfers loads safely to the subgrade. The base layer is the main layer of a road pavement, that receives and distributes traffic loads to the underlying layers and reduces the vertical compressive stresses which are loading the subgrade. Because of that, in road construction, the aggregate materials must be healthy and of high strength. Specifically, those used on the bituminous mixtures should have high strength and resistance to friction and impact, as well as a high polishing resistance index. Aggregate specifications are becoming increasingly stringent for materials used in the upper road pavement layers (bases), designed to support high-localized loading. The upper road pavement layers are also subject to greater influence from other external factors, such as atmospheric temperature [3]. In order to fulfill the above requirements, the quality control tests that were conducted in the examined aggregates focused on the estimation of their Geometrical, Physical and Mechanical properties. 


\section{Location of the Sampling Areas}

The examined aggregates were sampled from the areas of Methana and Agioi Theodoroi, located in the northeastern part of Peloponnese, next to Athens, Greece (Figure 1). Methana is part of the northwest edge of the Aegean volcanic arc. The volcanic activity in Methana was strongly revived during the Middle Pleistocene with the most recent volcanic activity occurred in 230 BC, creating the basaltic andesite of Kammeni Chora. The biggest part of the peninsula is covered from igneous rocks such as andesites and dacites. Three lithological types were sampled from four different locations and a total of nine samples were finally collected. More specifically, sampling involved four samples of andesites, one sample of basaltic andesite and four samples of dacites (Figure 2). Agioi Theodoroi area is mainly covered by limestones, dolomites, serpentinites and peridotites, marls, flysch, and dacites Petrounias et al. [4]. From this area, samples were collected from two different locations and consisted of dacite rocks (Figure 3) (Figures 1,2,3).

Figure 1: Sampling areas of Methana and Agioi Theodoroi in Greece.

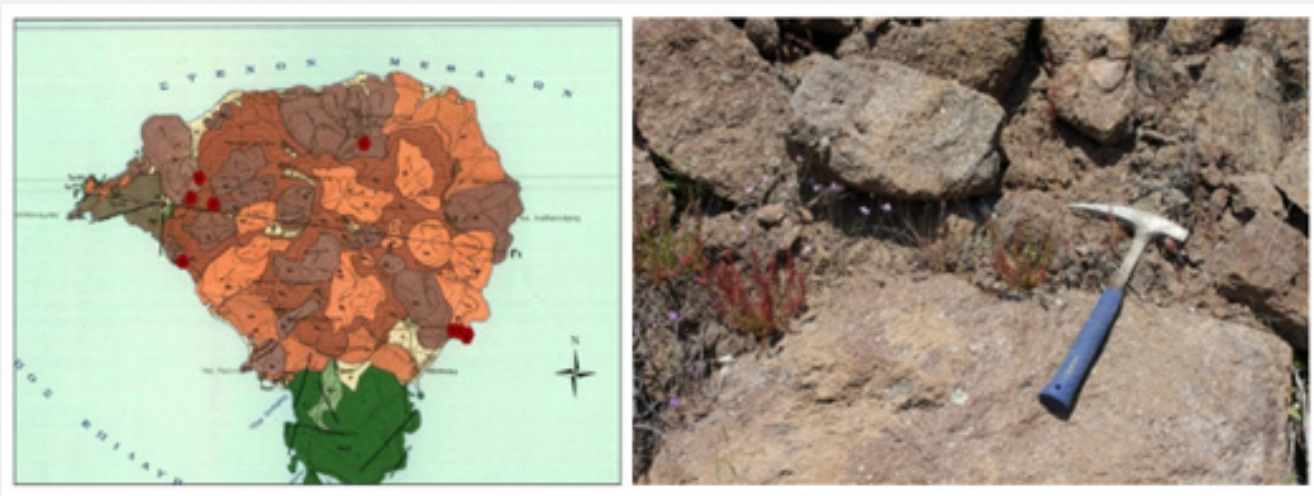

Figure 2: Sampling areas (red spots) and andesite outcrops in Methana.

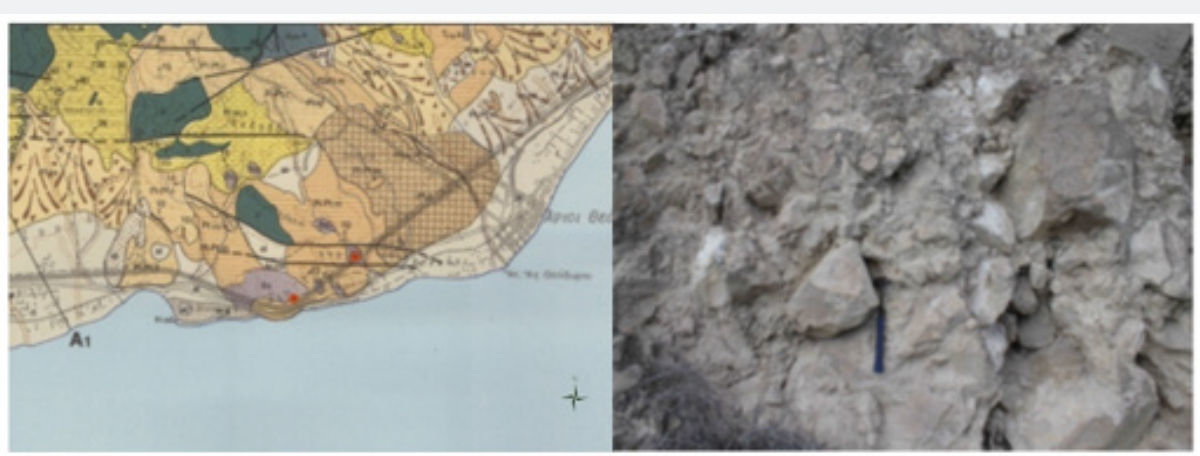

Figure 3: Sampling areas (red spots) and dacite outcrops in Agioi Theodoroi. 


\section{Methods and Materials}

Initially, block samples were collected from the outcrops of the referred geological formations (total block sample weight per site over $50 \mathrm{~kg}$ ) and were broken in the lab into smaller for further processing in the rock crusher. Then, with the help of the crusher and the appropriate setting, particles of $14 \mathrm{~mm}$ diameter or smaller were created. By using the appropriate sieves, the necessary quantity of the required material for each laboratory test was finally collected. Laboratory tests that were carried out in the sampling material focused mainly on:

1. Calculation of Water Absorption $\left(\mathrm{W}_{\mathrm{a}}\right)$ and Apparent Density $\left(\rho_{\mathrm{a}}\right)$

2. Particle shape test for the calculation of Flakiness Index (IF)

3. Sand Equivalent (SE) test for the determination of clay lumps

4. Los Angeles Abrasion test (LAAV)

5. Micro-Deval (MD) test

6. Aggregate Impact Value (AIV) test

7. Uniaxial Compressive Strength (UCS) test

Three of the most important tests conducted for aggregate quality control is the Los Angeles Abrasion test (LAAV), the MicroDeval test and the Aggregate Impact Value (AIV) test, with their devices presented in Figure 4. The Los Angeles Abrasion Value is one of the most common test methods used to calculate aggregate toughness and abrasion characteristics and determination of aggregates resistance to fragmentation in dry conditions. The total sample mass was about $5000 \mathrm{~g}$ for each sample and after 500 revolutions in the device, the mass loss of aggregate was calculated.
A lower numerical value of LAAV index indicates a more resistant material

$$
L A A V=\left(\frac{A-B}{A}\right) 100
$$

$\mathrm{A}=$ initial weight in gr of oven-dried sample

$\mathrm{B}=$ weight in gr of fraction retained on $1.70 \mathrm{~mm}$ sieves

A similar test method is the Micro-Deval test, which provides a measure of evaluation of the anti-abrasion resistance and durability of aggregate by measuring the mass change in the aggregate using steel ball in the water. Many aggregates could be scuffed easily in a moisturized condition than in a dry condition. Compared to Los Angeles abrasion test, it could reflect the anti-abrasion performance of aggregate better and had higher discrimination [5]. The calculation formula for the Micro-Deval test is:

$$
\text { Micro-Deval }=\left(\frac{500-m}{500}\right) 100
$$

$\mathrm{m}=$ the mass of sample retained in $1.6 \mathrm{~mm}$ sieve

The Aggregate Impact Value (AIV) measures the strength of aggregates and gives a relative measure of the resistance to sudden shock or impact and to granulation or pulverization (Koukis et al, 2007). For the preparation of this test, a range of 10-14 mm diameter aggregate used. Then, manually a hammer dropped freely 15 times at a rate of about 1 drop per second and the rock wear of the aggregates were measured, according to this formula:

$$
A I V=\left(\frac{M_{1}}{M_{2}}\right) 100
$$

$M_{1}=$ initial weight of the sample

$\mathrm{M}_{2}=$ weight of sample passing $2.36 \mathrm{~mm}$ sieve

(Figure 4)

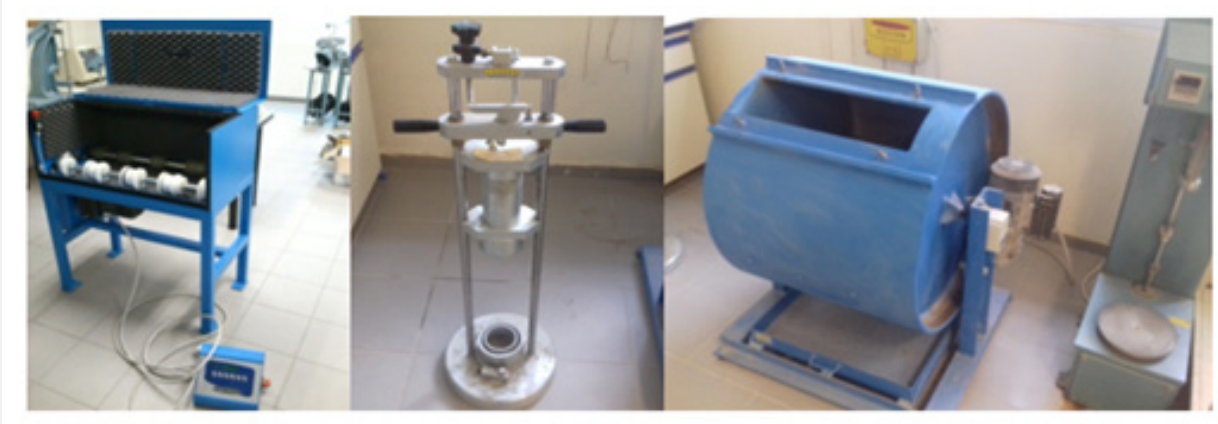

Figure 4: Micro-Deval, AIV and Los Angeles Device (Laboratory of Engineering Geology, Patras University).

\begin{tabular}{|c|c|c|c|c|c|c|c|c|}
\hline \multirow{2}{*}{ Rock Samples } & \multicolumn{8}{|c|}{ Aggregate Test } \\
\hline & $I_{F}(\%)$ & SE(\%) & $\rho_{\mathrm{a}}\left(\mathrm{g} / \mathrm{cm}^{3}\right)$ & $W_{a}(\%)$ & MD(\%) & LAAV(\%) & $\operatorname{AIV}(\%)$ & $\sigma_{\mathrm{c}}(\mathrm{MPa})$ \\
\hline METH.1 (andesite) & 12 & 76 & 2.78 & 3.56 & 18.02 & 54.17 & 32.65 & \multirow{3}{*}{$50-86$} \\
\hline METH.3 (andesite) & 15 & 76 & 2.57 & 3.01 & 25.08 & 54 & 39.38 & \\
\hline METH.8 (andesite) & 12 & 79 & 2.62 & 4.39 & 18.16 & 46.31 & 32.35 & \\
\hline
\end{tabular}

\section{Test Results}

Table 1: Results of laboratory tests. 


\begin{tabular}{|c|c|c|c|c|c|c|c|c|}
\hline METH.9 (andesite) & 16 & 71 & 2.19 & 5.3 & 31.49 & 51 & 41.59 & 17.84 \\
\hline $\begin{array}{c}\text { METH.7 (basaltic } \\
\text { andesite) }\end{array}$ & 6 & 79 & 3.14 & 0.45 & 3.78 & 15.3 & 110 \\
\hline METH.2 (dacite) & 7 & 77 & 2.7 & 3.36 & 44.64 & 43 & 26.5 \\
\hline METH.5 (dacite) & 15 & 73 & 2.35 & 5.04 & 52.32 & 67.9 & 37.07 \\
\hline METH.6 (dacite) & 9 & 57 & 2.23 & 3.27 & 26.54 & 58.56 & 28 \\
\hline METH.10 (dacite) & 19 & 76 & 2.2 & 5.44 & 57.1 & 73 & 45 \\
\hline AGTH1 (dacite) & 10 & 81 & 2.64 & 3.65 & 26.87 & 37.08 & 28.3 \\
\hline AGTH2 (dacite) & 16 & 74 & 2.19 & 5.54 & 54.6 & 75.3 & 41 \\
\hline $\begin{array}{c}\text { Specification limits } \\
\text { for road pavement } \\
\text { layers (ELOT) }\end{array}$ & $\begin{array}{c}\leq 35 \text { (coarse } \\
\text { aggregate) }\end{array}$ & $\begin{array}{c}>40 \% \text { (fine } \\
\text { aggregate) }\end{array}$ & - & - & - & $\leq 40$ (base) & - \\
\hline
\end{tabular}

All results, obtained from the laboratory tests mentioned before, along with the limits of the Hellenic Technical Specification ELOT 1501-05-03-05-01, are presented in the table below (Table 1): (Table 1)

Test results indicate that the andesite rocks present a better mechanical behavior compared with the dacite rocks. Andesite rocks have lower values of MD, LAAV, and AIV compared with dacite rocks, indicating better strength and quality. The range of LAAV test for the andesite rocks was 15,3\%-54,17\% and for the Uniaxial compressive strength $50-110 \mathrm{MPa}$. The range of LAAV test for the dacite rocks was $37,08 \%-75,3 \%$ and for the Uniaxial compressive strength was 25-50 MPa.

\section{Correlations Between the Aggregate Properties}

In order to study the interrelationships between the physical, geometrical and mechanical properties of the examined aggregates, a regression analysis was applied to the properties data. Regression analysis is a statistical tool, which estimates the relationships between the variables and mainly focuses on the relationship between a dependent variable and one or more independent variables. It examines the linear relationship between a metricscaled dependent variable (also called endogenous, explained, response, or predicted variable) and one or more metric-scaled independent variables [6]. The correlations between the mechanical properties of the aggregates show a positive correlation between the AIV - MD, and MD-LAAV for both the Andesites and the Dacites, with high correlation coefficient R2, especially in the Andesite rock samples (Figure 5). As the resistance index increases, there is more rock wear and the values of the mechanical properties' indexes increase, which mean a lower strength and quality of the aggregates. The correlations between the mechanical and the geometrical properties of the aggregates show a positive correlation between the Flakiness Index (IF) and the AIV - LAAV indexes, with high correlation coefficient $\mathrm{R} 2$ for both the Dacites and Andesites (Figure 6). As the flakiness index increases, mechanical properties' indexes, LAAV-MD-AIV increase as well, which mean a lower strength and quality of the aggregates due to their elongated particles $[7,8]$. The correlations between the mechanical and the physical properties of the aggregates show a positive correlation between the Water Absorption and the Micro-Deval - LAAV indexes (Figure 7). On the other hand, the correlations between Apparent Density and the AIV - LAAV indexes show negative correlation because as the apparent density increases, the mechanical properties indexes decrease, which mean a higher strength and quality of the aggregates (Figure 8) (Figure 5-8) (Table 2).

Table 2: Interrelationships between the properties of the examined aggregate samples.

\begin{tabular}{|c|c|c|c|c|c|c|}
\hline & \multicolumn{2}{|c|}{ Data } & \multicolumn{4}{|c|}{ Correlations } \\
\hline & \multirow{2}{*}{$\mathbf{X}$} & \multirow{2}{*}{$\mathbf{Y}$} & \multicolumn{2}{|l|}{ Dacites } & \multicolumn{2}{|c|}{ Andesites } \\
\hline & & & Relationships & $\mathbf{R}^{2}$ & Relationships & $\mathbf{R}^{2}$ \\
\hline 1 & $I_{F}$ & AIV & $\mathrm{AIV}=1.65 \mathrm{IF}+13.5$ & $\mathrm{R}^{2}=0.97$ & $\mathrm{AIV}=2.38 \mathrm{I}_{\mathrm{F}}+3.5$ & $\mathrm{R}^{2}=0.99$ \\
\hline 2 & $\mathrm{I}_{\mathrm{F}}$ & LAAV & $\mathrm{LAAV}=2.88 \mathrm{IF}+22.7$ & $\mathrm{R}^{2}=0.71$ & $\mathrm{LAAV}=3.80 \mathrm{I}_{\mathrm{F}}-2.5$ & $\mathrm{R}^{2}=0.81$ \\
\hline 3 & $\mathrm{I}_{\mathrm{F}}$ & MD & $\mathrm{MD}=2.23 \mathrm{IF}+15.4$ & $\mathrm{R}^{2}=0.57$ & $\mathrm{MD}=2.61 \mathrm{I}_{\mathrm{F}}-12.8$ & $\mathrm{R}^{2}=0.97$ \\
\hline 4 & $\rho_{\mathrm{A}}$ & AIV & $\mathrm{AIV}=-24.43 \rho \alpha+92.6$ & $\mathrm{R}^{2}=0.51$ & AIV $=-25.04 \rho_{\alpha}+99.4$ & $\mathrm{R}^{2}=0.87$ \\
\hline 5 & $\rho_{\mathrm{A}}$ & LAAV & LAAV $=-63.58 \rho \alpha+210.8$ & $\mathrm{R}^{2}=0.83$ & LAAV $=-35.42 \rho_{\alpha}+138.4$ & $\mathrm{R}^{2}=0.55$ \\
\hline 6 & $\mathrm{~W}_{\mathrm{a}}$ & AIV & $\mathrm{AIV}=7.05 \mathrm{Wa}+3.4$ & $\mathrm{R}^{2}=0.94$ & $\mathrm{AIV}=4.52 \mathrm{~W}_{\mathrm{a}}+17.4$ & $\mathrm{R}^{2}=0.70$ \\
\hline 7 & $\mathrm{~W}_{\mathrm{a}}$ & LAAV & $\mathrm{LAAV}=12.68 \mathrm{Wa}+3.5$ & $\mathrm{R}^{2}=0.72$ & $\mathrm{LAAV}=7.58 \mathrm{~W}_{\mathrm{a}}+18.4$ & $\mathrm{R}^{2}=0.63$ \\
\hline 8 & $\mathrm{~W}_{\mathrm{a}}$ & MD & $\mathrm{MD}=11.02 \mathrm{Wa}-4.6$ & $\mathrm{R}^{2}=0.73$ & $\mathrm{MD}=5.15 \mathrm{~W}_{\mathrm{a}}+1.8$ & $\mathrm{R}^{2}=0.73$ \\
\hline 9 & AIV & MD & $\mathrm{MD}=1.46 \mathrm{AIV}-6.3$ & $\mathrm{R}^{2}=0.68$ & $\mathrm{MD}=1.10 \mathrm{AIV}-16.6$ & $\mathrm{R}^{2}=0.97$ \\
\hline 10 & AIV & LAAV & LAAV = 1.79AIV -2.2 & $\mathrm{R}^{2}=0.76$ & $\mathrm{LAAV}=1.61 \mathrm{AIV}-8.5$ & $\mathrm{R}^{2}=0.82$ \\
\hline 11 & MD & LAAV & $\mathrm{LAAV}=0.84 \mathrm{MD}+22.3$ & $\mathrm{R}^{2}=0.53$ & $\mathrm{LAAV}=1.35 \mathrm{MD}+18.2$ & $\mathrm{R}^{2}=0.71$ \\
\hline
\end{tabular}



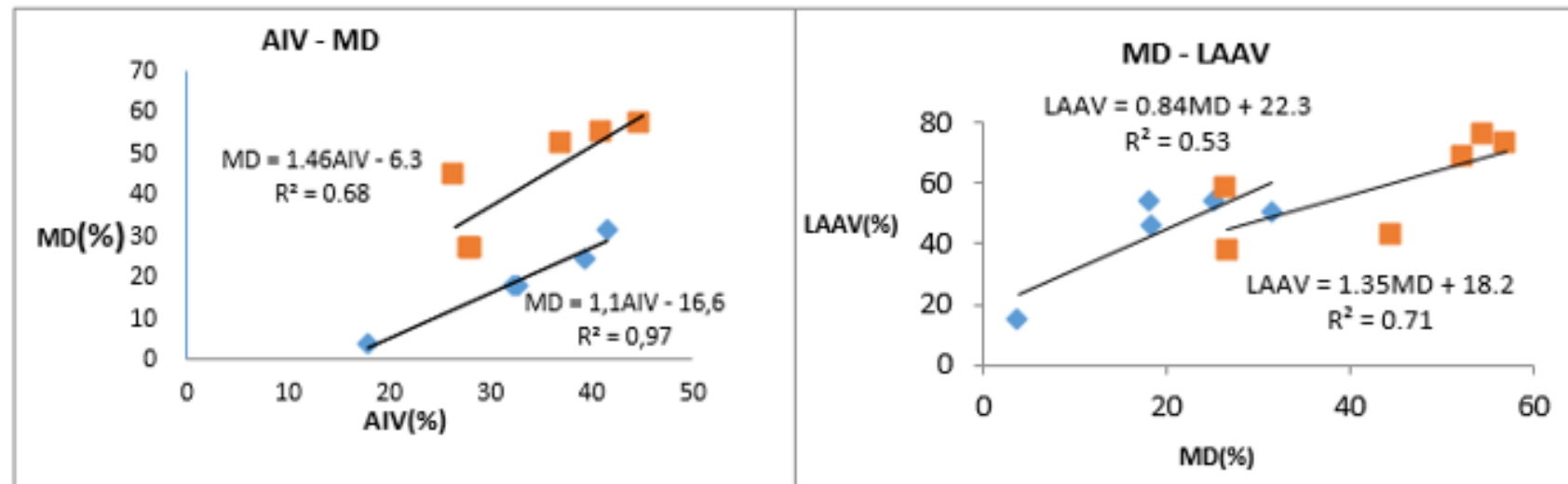

Figure 5: Correlations between mechanical properties of the aggregate samples.

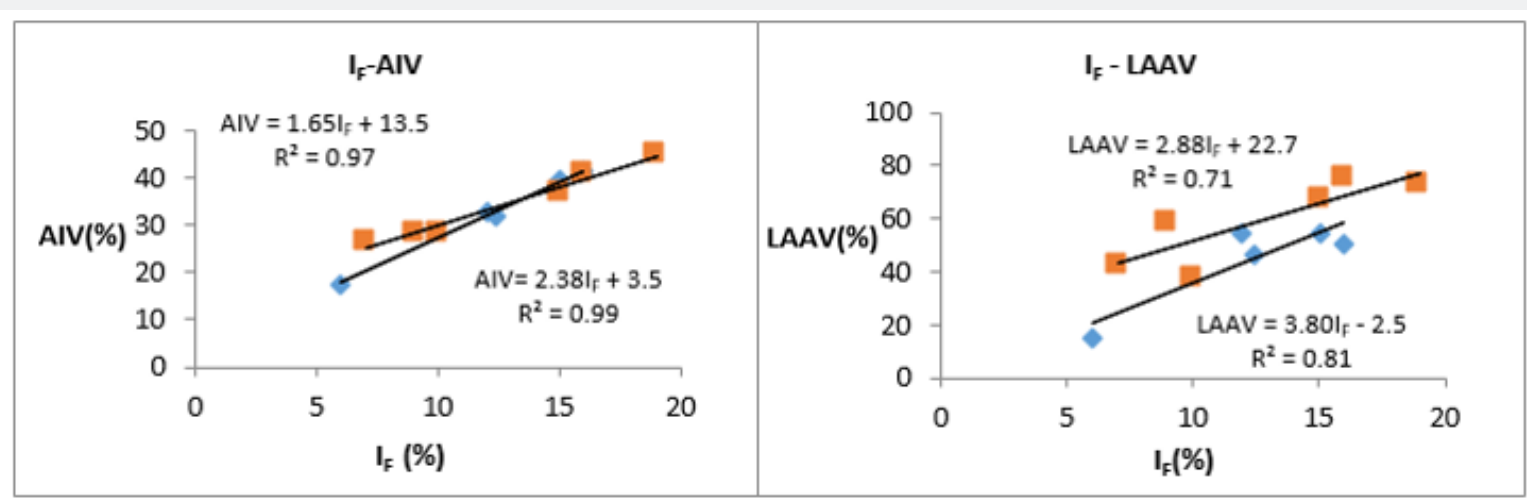

Figure 6: Correlations between geometrical and mechanical properties of the aggregate samples.

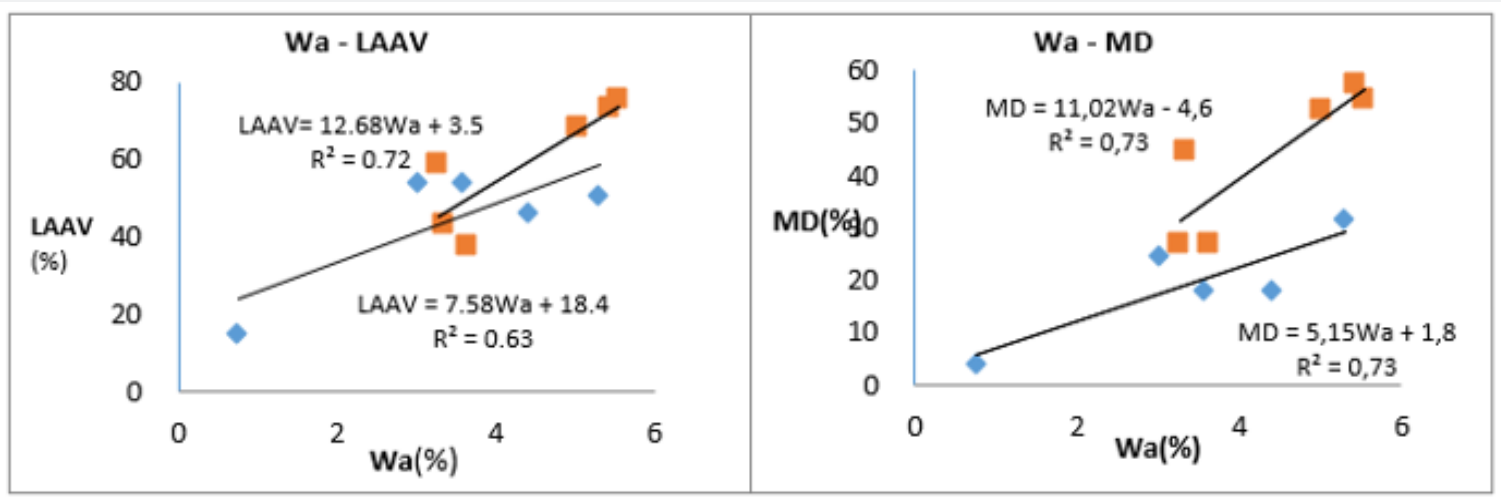

Figure 7: Correlations between physical (Wa) and mechanical properties of the aggregate samples.

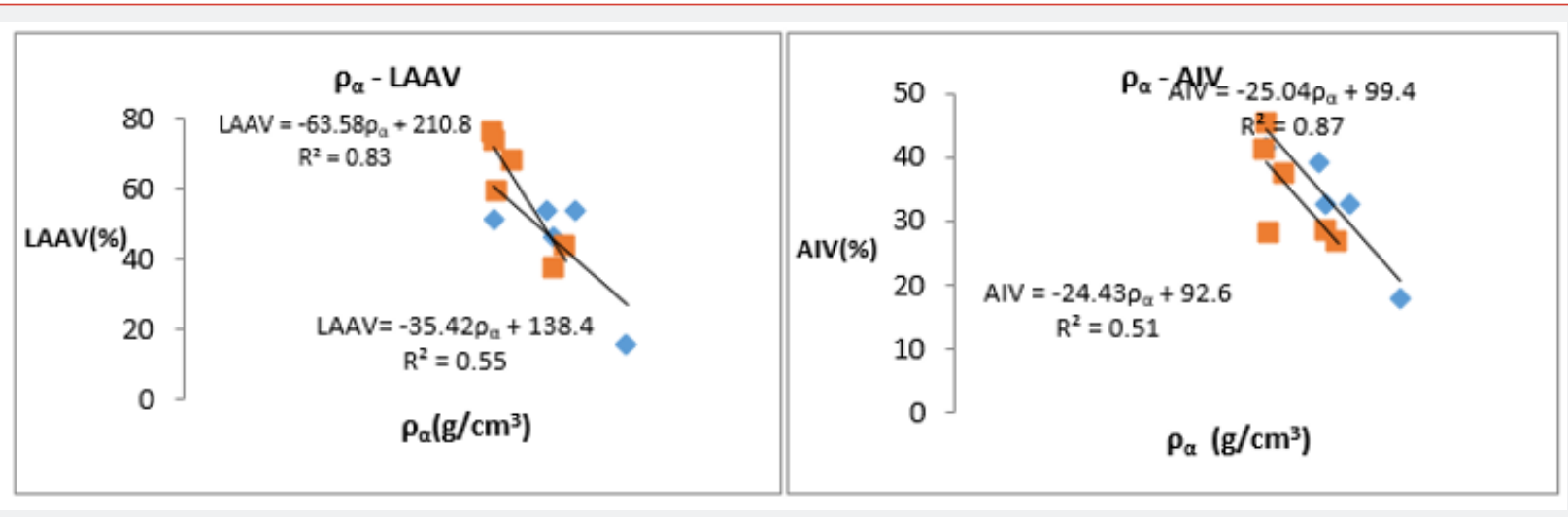

Figure 8: Correlations between physical $(\rho \alpha)$ and mechanical properties of the aggregate samples. 


\section{Conclusion}

The suitability of several igneous rocks for their potential use as aggregates in road pavement layers in Greece was examined by conducting quality control tests under the specific guidelines of Hellenic Technical Specifications (ELOT) for aggregate properties determination. The laboratory testing results led to the general conclusion that the most samples obtained from the andesite and dacite rocks cannot be used as aggregates in road pavement layers, due to their high Los Angeles Abrasion Values (LAAV). However, some of the collected samples were determined as suitable for use in subbase road pavement layers, and some other samples as suitable for use in base road pavement layers. Andesite rock samples determined to have better physical, geometrical and mechanical properties than the dacite rock samples. In order to study the interrelationships between the physical, geometrical and mechanical properties of these materials, regression analysis was applied to their properties data and the results show significant interrelationships between those properties. The correlation coefficient was high in most of the samples, which means a high correlation between the properties of the aggregates. Especially, the correlations between Apparent Density and the AIV - LAAV indexes show negative correlation, which mean a higher strength and quality of the examined aggregates.

\section{Acknowledgement}

None.

\section{Conflicts of Interest}

No conflict of interest.

\section{References}

1. Koukis G, Sabatakakis N (2007) Geology of technical works. Technical book ed. Papasotiriou, 623 pages.

2. Koukis G. Sabatakakis N, Spyropoulos A (2007) Resistance variation of low-quality aggregates. Bulletin of Engineering Geology and Environment 66: 457-466.

3. Hill A, Dawson A, Mundy M (2001) Utilisation of aggregate materials in road construction and bulk fill. Journal of Resources, Conservation and Recycling 32(3-4): 305-320.

4. Petrounias P, Rogkala A, Kalpogiannaki M, Tsikouras B, Hatzipanagiotou K (2016) Comparative study of Physicomechanical properties of ultrabasic rocks and andesites from central Macedonia (Greece) Bulletin of the Geological Society of Greece pp.1989-1998 Proceedings of the 14th International Congress, Thessaloniki.

5. Jiangfeng W, Yue H, Linbing W, Meng G, Lingjian M, et al. (2017) Analysis of coarse aggregate performance based on the modified micro Deval abrasion test. International Journal of Pavement Research and Technology 11: 185-194.

6. Skiera B, Reiner J, Albers S (2018) Regression Analysis. Handbook of Market Research pp.1-29.

7. Sabatakakis N, Koukis G, Spyropoulos A (2005) Quality assessment of Pleio-Pleiostocene and recent Quaternary coarse-grained sediments as aggregates for road construction. Proceedings of the International Symposium Geoline 2005: Geology and linear infrastructures, Lyon, p.7.

8. Hellenic Technical Specifications ELOT 1501-05-03-05-01 (2009) Road pavement layers with unbound aggregates. 